time. Following up with undecided patients is also critical.

What is most important is that we family physicians integrate ACP with our patients, exploring what works best in context of our own practices.

Marc Tunzi, MD, MA

Natividad Medical Center, Salinas, California and the Department of Family and Community Medicine, University of California, San Francisco, San Francisco, CA

William Ventres, MD, MA Department of Family and Preventive Medicine, University of Arkansas for Medical Sciences, Little Rock, AR

doi: 10.3122/jabfm.2019.04.190110

To see this article online, please go to: http://jabfm.org/content/ 32/4/000.full.

\section{Re: Better Doctor-Patient Relationships Are Associated with Men Choosing More Active Depression Treatment}

To the Editor: I commend David Kealy and colleagues ${ }^{1}$ on their work on the doctor-patient relationship and men's choice of depression treatment. However, I do have a few concerns that would benefit from clarification.

First, the gender of the physician is an important covariate that should be accounted for in any doctorpatient relationship, as it affects this dynamic and its outcomes. $^{2}$ Roter and colleagues ${ }^{3}$ showed that female physicians engaged the patient in more positive conversation, gave more information, and built more partnership compared with the male physician; similarly, when patients are with female physicians, patients engage in more positive discussion and partnership building compared with male physicians. ${ }^{3}$ This article highlights men's choice regarding treatment and the relationship with their physician; controlling for the physician's gender could help improve the understanding of this doctorpatient relationship.

Second, the questionnaire implied that primary care doctors would administer the hypothetical treatment preference. Although I agree that primary care doctors often manage treatment-resistant depression, ${ }^{4}$ there exists a substantial section of the population that are referred to psychiatrists by primary care doctors. ${ }^{5}$ This article does not account for this population, especially given that attitudinal differences exist in managing depression and in terms of "professional ease in dealing with patients with depression" between general practitioners and psychiatrists. ${ }^{6}$ Thus, although the findings may apply to the primary care population, it excludes the treatment of depression in men managed by psychiatrists.

Ayodeji Otufowora, MBBS, MPH, CPH

Department of Epidemiology, College of Public Health and Health Professions and College of Medicine, University of Florida, Gainesville, FL, USA
To see this article online, please go to: bttp://jabfm.org/content/ 32/4/000.full.

\section{References}

1. Kealy D, Rice SM, Ferlatte O, Ogrodniczuk JS, Oliffe JL. Better doctor-patient relationships are associated with men choosing more active depression treatment. J Am Board Fam Med 2019;32:13-9.

2. Bertakis KD. The influence of gender on the doctor-patient interaction. Patient Educ Couns 2009;76:356-60.

3. Roter D, Lipkin M Jr., Korsgaard A. Sex differences in patients' and physicians' communication during primary care medical visits. Med Care. 1991;29:1083-93.

4. Schwenk TL, Evans DL, Laden SK, Lewis L. Treatment outcome and physician-patient communication in primary care patients with chronic, recurrent depression. Am J Psychiatry 2004;161:1892-901.

5. Peterson BD, Pincus HA, Suarez A, Zarin DA. Datapoints: referrals to psychiatrists. Psychiatr Serv 1998;49:449-449.

6. Kerr M, Blizard R, Mann A. General practitioners and psychiatrists: comparison of attitudes to depression using the depression attitude questionnaire. Br J Gen Pract 1995; 45:89-92.

doi: 10.3122/jabfm.2019.04.190079

The above letter was referred to the author of the article in question, who offers the following reply.

\section{Response: Re: Better Doctor-Patient Relationships Are Associated with Men Choosing More Active Depression Treatment}

To the Editor: We thank Dr. Otufowora for commenting on our work regarding the doctor-patient relationship and men's choice of depression treatment ${ }^{1}$ and for raising concerns about the potential role of the physician's gender and the specialist status of the treatment provider.

Rather than address the abovementioned questions, our study focused on men's overall experience of the quality of their relationship with their family physician. Although female physicians may be perceived as more caring with regard to depression management, ${ }^{2}$ some research suggests complex interactions between patient and physician gender and whether the physician adopts a patient-centered orientation. ${ }^{3}$ Thus, although gender matters, the nature of the doctor-patient communication is also important. We suspect similar interactions regarding the treatment contextwhether primary care physician or mental health specialist-in that the quality of the relationship would remain influential. Indeed, research has shown considerable "provider effects" among psychiatrists, with some achieving superior outcomes prescribing placebo to others prescribing antidepressants. ${ }^{4}$

Considering the risks for suicide and atypical depression presentations among men, ${ }^{5}$ a better understanding of men's treatment engagement-including 
the role of the doctor-patient relationship in different treatment contexts-is urgently needed. ${ }^{6}$ Our study indicated that the degree to which men feel their family physician cares for and understands them is associated with their motivation to pursue treatment. We hope this finding will stimulate further interest in investigating men's experience of the doctor-patient relationship, while bolstering family physicians' confidence in the time-honored practice of forging responsive therapeutic relationships.

David Kealy, PhD, and John S. Ogrodniczuk, PhD Department of Psychiatry, University of British Columbia, Vancouver, Canada Simon M. Rice, $\mathrm{PhD}$

The National Centre of Excellence in Youth Mental Health, Centre for Youth Mental Health, The University of Melbourne, Melbourne, Australia Olivier Ferlatte, PhD, and John L. Oliffe, PhD School of Nursing, University of British Columbia, Vancouver, Canada

To see this article online, please go to: http://jabfm.org/content/ 32/4/000.full.

\section{References}

1. Kealy D, Rice SM, Ferlatte O, Ogrodniczuk JS, Oliffe JL. Better doctor-patient relationships are associated with men choosing more active depression treatment. J Am Board Fam Med 2019;32:13-9.

2. Parker GB, Hyett MP. Management of depression by general practitioners: impact of physician gender. Aust NZ J Psychiatry 2009;43:355-9.

3. Roter DL, Erby LH, Adams A, Buckingham CD, Vail L, Realpe A, Larson S, Hall JA. Talking about depression: an analogue study of physician gender and communication style on patient disclosures. Patient Educ Couns 2014;96: 339-45.

4. McKay KM, Imel ZE, Wampold BE. Psychiatrist effects in the psychopharmacological treatment of depression. J Affect Disord 2006;92:287-90.

5. Rice SM, Kealy D, Oliffe JL, Ogrodniczuk JS. Externalizing depression symptoms among Canadian males with recent suicidal ideation: a focus on young men. Early Interv Psychiatry 2018;13:308-313.

6. Seidler ZE, Rice SM, Ogrodniczuk JS, Oliffe JL, Dhillon HM. Engaging men in psychological treatment: A scoping review. Am J Mens Health 2018;12:1882-900.

doi: 10.3122/jabfm.2019.04.190140

\section{Re: Impact of a Rapid Point of Care Test for Influenza on Guideline Consistent Care and Antibiotic Use}

To the Editor: Dear Editor, we read the publication on "Impact of a Rapid Point of Care Test for Influenza on Guideline Consistent Care and Antibiotic Use" with a great interest. ${ }^{1}$ Dale concluded that, "independent of test outcome, patients who received the test were more likely to receive an antiviral and less likely to receive an antibiotic or have a return visit within 2 weeks." ${ }^{1} \mathrm{We}$ would like to share ideas on this report. In our setting in tropical Indochina, influenza is very common and the diagnosis is usually primarily done by clinical decision. In primary health care center, the PCR point of care testing is usually not available and the cost of the test is considered high and not affordable. Most patients are examined and if there is any suspicious clinical feature viral infection, the anti-influenza drug might be used. This practice might result in unnecessary use of antiviral drug but it is better than waiting for a very long time for getting the confirmation of influenza test result from referring referencing laboratory. Regardless of final diagnosis, the patients usually inquire for getting antiviral drug. ${ }^{2}$ Nevertheless, another important problem is the effectiveness of antiviral drug due to the problem of drug resistance. ${ }^{2}$ How to implement the low cost point of care PCR test for influenza is usually a big question. To serve the need in primary health care center, a cost-effective point of care test should be searched for.

Sora Yasri, PhD

KMT Primary Care Center, Bangkok Thailand Viroj Wiwanitkit, MD

Dr DY Patil University, Pune, India

To see this article online, please go to: http://jabfm.org/content/ 32/4/000.full.

\section{References}

1. Dale AP, Ebell M, McKay B, et al. Impact of a rapid point of care test for influenza on guideline consistent care and antibiotic USE. J Am Board Fam Med 2019;32;226-233.

2. Wiwanitkit V. Rates and effectiveness of antiviral use among hospitalized influenza patients. Expert Rev Anti Infect Ther 2015;13:835-842.

doi: 10.3122/jabfm.2019.04.190089

The above letter was referred to the author of the article in question, who offers the following reply.

\section{Response: Re: Impact of a Rapid Point of Care Test for Influenza on Guideline Consistent Care and Antibiotic Use}

To the Editor: We thank Yasri and Wiwanitkit for their response regarding our publication on "Impact of a Rapid Point of Care Test for Influenza on Guideline Consistent Care and Antibiotic Use." ${ }^{1}$ A cost-effective point of care test is necessary to increase guideline consistency of care. Yasri and Wiwanitkit make an excellent point about the transferability of our findings to other primary care settings throughout the world where access to point of care testing may be limited. The emerging issue of drug resistance is an important consideration, particularly when diagnoses must be made solely on clinical judgment. Currently, drug 